\title{
CALENDAR OF COMPUTER-GAMES EVENTS 1995
}

\author{
April 26-28; May 1-3 \\ The 1995 AEGON Man-Computer Tournament, to be held in The Hague, The Netherlands. \\ Details from Cock de Gorter, Valkenboskade 607, 2563 JE The Hague, The Netherlands, Telephone: +31- \\ $70-4643729$.
}

\section{May 25-29}

The $8^{\text {th }}$ World Computer Chess Championship, to be held in Hong Kong, Japan.

Details from David N.L. Levy, 89, Constantine Road, London NW3 2LP England. Email: DavidL@intrsrch.demon.co.uk. Fax: (+44) 714820672.

\section{October 14-15}

The $6^{\text {th }}$ Harvard Cup, to be held at the Computer Museum in Boston, USA.

Details from Christopher Chabris, P.O. Box 2967, Harvard Square Station, Cambridge, Ma 02238, USA. Email: cfc@isr.harvard.edu. Telephone: 617-876-5759, Fax: 617-491-9570.

\section{INTERNATIONAL COLLOQUIUM: BOARD GAMES IN ACADEMIA}

April 9-13, 1995,

\author{
Leiden, The Netherlands
}

The International Colloquium on "Board Games in Academia" invites all scholars interested in game research to submit articles, in particular those scholars who utilize board games in their specific disciplines. The Colloquium intends to discuss the role of board games in academic research and will try to enhance the multi-disciplinary co-operation in games research. All scholars who wish to participate with a presentation of their article are requested to submit abstracts before February 1, 1995. All abstracts should be written in English and not exceed 500 words. All participants receive a copy of the abstract book at the start of the Colloquium.

Those scholars who wish to write descriptive articles on games are requested to submit their articles before April 30, 1995. These articles will be published in the proceedings of the Colloquium. Priority to the acceptance of articles will be given to articles related to the theme of the colloquium, i.e., those scholars who wish to write on the role of board games in their discipline of academic research. These researchers are requested to submit their theme related articles before February 15, 1995. These articles will be published prior to the Colloquium. If abstracts and/or articles are accepted the contributors are requested to present their findings at the Colloquium. Presentations are given in English and do not exceed 30 minutes. All speakers will receive a complimentary copy of their publication and they enjoy priority over other participants with their hotel reservations and other preferances.

\section{Notes for Contributors}

Contributions in English are invited. The length of papers should not exceed 15 pages (double spaced) size A4. Where possible submissions of the paper on disk in addition to the typed manuscript would be appreciated. Apple Macintosh compatible 3.5" disks are accepted; formatted in 'word'. Figures/Tables: Black and white figures must be drawn to a standard suitable for direct reproduction. Coloured figures and photographs can be accepted only if the author provides funding to cover the costs of reproduction. Tables should be drawn without vertical or horizontal rules and contents should be spaced to aid clarity. The approximate position of the table in the text should be shown in the margin of the typescript. It is the author's responsibility to obtain copyright clearance for reproduction of figures and tables and to ensure adequate acknowledgement.

Footnotes should not be included. Notes may appear at the end of the main text numbered with Arabic numerals. The Colloquium follows the Harvard system for references: in the text, in brackets, author's name and date of work: in the alphabetical reference list at the end of the paper, name and initials of the author, year of publication, title of book, place of publication, publisher. Page numbers for reference in the text are necessary only in the case of direct quotations. If the reference is to a periodical the title should be given, volume in Arabic numerals, part number and page numbers. If in doubt, consult the Chicago Manual of Style. For more information and registration forms: A.J. de Voogt, Da Costalaan 1, 3743 HT Baarn. Telephone +31 (0)215416377. 